\title{
Nutritional Anthropometry
}

National Cancer Institute

\section{Source}

National Cancer Institute. Nutritional Anthropometry. NCI Thesaurus. Code C15826.

The study of nutritional effects upon the size, weight, and proportions of the human body. 